\title{
Brains, Lifestyles and Cognition: Are There General Trends?
}

\author{
Louis Lefebvre $^{\mathrm{a}}$ Daniel Sol ${ }^{\mathrm{b}}$ \\ ${ }^{a}$ Department of Biology, McGill University, Montréal, Qué., Canada; ${ }^{b}$ CREAF (Research Center for \\ Forestry Applications), Autonomous University of Barcelona, Barcelona, Catalonia, Spain
}

\author{
Key Words \\ Brain $\cdot$ Evolution $\cdot$ Neuroecology $\cdot$ Cognition
}

\begin{abstract}
Comparative and experimental approaches to cognition in different animal taxa suggest some degree of convergent evolution. Similar cognitive trends associated with similar lifestyles (sociality, generalism, new habitats) are seen in taxa that are phylogenetically distant and possess remarkably different brains. Many cognitive measures show positive intercorrelations at the inter-individual and inter-taxon level, suggesting some degree of general intelligence. Ecological principles like the unpredictability of resources in space and time may drive different types of cognition (e.g., social and non-social) in the same direction. Taxa that rank high on comparative counts of cognition in the field are usually the ones that succeed well in experimental tests, with the exception of avian imitation. From apes to birds, fish and beetles, a few common principles appear to have influenced the evolution of brains and cognition in widely divergent taxa.

Copyright $\odot 2008$ S. Karger AG, Basel
\end{abstract}

\section{Introduction}

Why do some animal taxa have larger brains than others? Body size allometry and grade shifts account for most of the variance in brain size, but a substantial pro- portion remains when these variables are factored out. What is behind this remaining variance? Because the brain is an organ that processes, stores and integrates sensory, motor and information, the most obvious hypothesis is that there are cognitive advantages in affording larger brains [Jerison, 1973]. Important advances have been made since Jerison's pioneering work, but several unresolved issues still stimulate debates among contemporary researchers. Are cognitive activities selected as independent modules or can they be part of more general processes that cause some animals to consistently outrank others in several cognitive measures? What are the evolutionary forces that select for larger brains? Are there convergent principles that govern the evolution of brain size in different taxa? Do whole brain size differences, as opposed to finer measures, mean anything in terms of cognitive performance?

Several research strategies have been used to answer these questions. Some use principles derived from work on humans, others focus on specialized behaviors (e.g., food storing) seen only in a few non-human taxa. In this paper, we review an approach initially developed with birds and based on field observations of innovative behaviors. We first discuss a series of operational measures of cognition, and ask whether variation in the measures suggests correlated or independent evolution. Next, we test whether these cognitive measures co-vary with the size of neural structures. Finally, we discuss some ecological contexts in which the cognitive measures associated with size of neural structures might be

\section{KARGER \\ Fax +4161306 1234 \\ E-Mail karger@karger.ch}

www.karger.com
(C) 2008 S. Karger AG, Basel

0006-8977/08/0722-0135\$24.50/0

Accessible online at:

www.karger.com/bbe
Louis Lefebvre

Department of Biology, McGill University

1205 avenue Docteur Penfield

Montréal, Qué., H3A 1B1 (Canada)

Tel. +1 514398 6457, Fax +1 514398 5069, E-Mail louis.lefebvre@mcgill.ca 
selected and ask whether the same contexts might explain the evolution of large brains in independent lineages.

\section{Operational Measures of Cognition}

Recent comparative work on correlates of brain size has focused on continuous operational measures of cognition. Although many of the pioneering studies of the 1980's used categorical life history and ecological variables [e.g., diet, Harvey et al., 1980; development mode, Bennett and Harvey, 1985; Iwaniuk and Nelson, 2003], the focus since the late 1990's has been on frequency counts of naturally-occurring behaviors in the wild. These measures include the propensity for social deception in primates [Byrne, 1993; Byrne and Corp, 2004], innovation in birds [Lefebvre et al., 1997a] and primates [Reader and Laland, 2002], social learning in primates [Reader and Laland, 2002] and tool use in birds [Lefebvre et al., 2002] and primates [Reader and Laland, 2002]. Given that animal cognition is extremely difficult to define, the strict operational nature of these comparative indices is an advantage; the indices simply measure variation on a continuum, without specifying thresholds beyond which behaviors can be considered 'intelligent' or 'complex' or which specific cognitive mechanisms are involved [Giraldeau et al., 2007]. Moreover, because the counts are based on field observations, these measures of cognition are biologically meaningful and comparable among species or higher taxonomic levels. Falsifiable predictions can then be made on the indices, for example that they are all positively correlated or that the size of certain brain areas is larger in taxa that have higher counts of innovation, tool use, deception and/or social learning.

Because the counts are based on case reports, these measures of cognition are vulnerable to a number of biases [reviewed in Lefebvre et al., 2004]. The importance of these biases needs to be rigorously evaluated before using the cognitive counts in analyses. In birds, for example, nine possible biases have been checked and found not to account for the positive correlation between innovation rate and residual brain, forebrain or mesopallium size [Nicolakakis and Lefebvre, 2000; Lefebvre et al., 2001]. The most important bias is that associated with the effort devoted by scientists to observing different species, but this effect can be mitigated by including a measure of research effort in multivariate models [Reader and Laland, 2002].
Because the above operational measures are based on anecdotal reports, they also need to be complemented by experiments. In general, frequency count and experimental approaches yield similar results. Taxa that rank high on innovation, tool use, deception and social learning counts tend to be those that succeed in experimental tests of sophisticated cognitive processes. For example, an anecdotal report on use of tools in New Caledonian crows [Orenstein, 1972] has been followed by extensive field work [Hunt, 1996; Hunt and Gray, 2004], as well as laboratory experiments [Weir et al., 2002; Kenward et al., 2005; Taylor et al., 2007] that have yielded detailed understanding of the most complex form of tool manufacture known in non-human animals. If New Caledonian crows are unique in their tool use, they are also part of the most innovative genus of the entire class Aves [Lefebvre et al., 1997a], as well as the genus that has the highest tool use count [Lefebvre et al., 2002]. In the New World, Quiscalus is the second most innovative passerine genus after Corvus. In line with this, Q. lugubris is, among the opportunistic birds of Barbados, the species that does best at innovative problem-solving [Webster and Lefebvre, 2001]; in field and aviary experiments, Q. lugubris also shows imitation [Lefebvre et al., 1997b], backward conditioning of alarm calls [Griffin and Galef, 2005], as well as flexible use of tool-like processing of dry food [Morand-Ferron et al., 2004, 2006, 2007a, b]. In primates, Pan troglodytes, the species that tops the comparative data bases on deception [Byrne and Whiten, 1988], innovation, tool use and social learning rate [Reader and Laland, 2002] is also the one that shows the most sophisticated behavior in experiments on cultural transmission [Bonnie et al., 2007], imitation [Whiten et al., 1996], and cooperation [Melis et al., 2006]. In the New World, the genus Cebus ranks high on all comparative counts [Reader and Laland, 2002], and uses rocks to dig up tubers [Moura and Lee, 2004] and crack open nuts [Fragaszy et al., 2004]; like chimpanzees [Lefebvre, 1982; Brosnan et al., 2008], they will barter with humans in captivity [Drapier et al., 2005]. Interspecifc comparisons on birds and primates show positive correlations between reversal learning, an experimental measure taken in captivity, and innovation rate, a frequency count taken in the field [Lefebvre et al., 2004]. For the moment, the major discrepancy between the experimental and count approaches to cognition seems to be in the field of avian imitation. In primates, the high rank of apes on frequency count scales is consistent with the fact that, in experiments, they show more cognitively demanding forms of social learning than do monkeys [e.g., imitation: Visalberghi and Fragaszy, 1990]. In birds, however, imitation 
has been demonstrated in species, e.g., pigeons and quail, that have both small brains and rank very low on innovation and tool use counts [Zentall, 2004].

\section{Variation among Animals}

One of the questions that has long worried psychologists is the modular or general-process nature of cognition. One purely empirical way of addressing this issue is to see if performance on different cognitive tasks across individuals or taxa shows positive, negative or zero correlations. In the first case, this means that there might be a common general process behind the positively correlated activities, or that the modular processes controlling each activity are selected together. Negative correlations would suggest trade-offs, such that enhancement of one type of cognition and/or memory is costly and requires a decrease in other types of cognition [Sherry and Schacter, 1987]. A zero correlation would imply that the systems are independent.

A surprising number of cognitive measures show positive correlations. For example, Reader and Laland [2002] showed that social learning, innovation and tool use counts are all positively correlated across primate species. Deaner et al. [2006] found a similar trend of positive correlations over primate genera for up to 30 different cognitive tests conducted in captivity. In birds, innovation rate is positively correlated with tool use [Lefebvre et al., 2002] and with performance on tests of problem-solving and reversal learning [Lefebvre et al., 2004]. For the moment, the negative relationship between food-storing and innovation in corvids and parids [Lefebvre and Bolhuis, 2003] stands out as an exception, even though it is based on a small sample. At the individual level, Bouchard et al. [2007] have found that latency of social learning is positively correlated with innovative problem-solving in pigeons, even after the common correlate of neophobia has been removed from the two measures. Positive correlations across individuals are a common feature of cognitive test batteries run on humans as well as outbred rodents [Plomin, 2001]. All these lines of evidence suggest that some of the variation in cognition between individuals and species reflects a general process. Finally, there seems to be strong agreement in the ranking of taxa in field and laboratory measures of cognition. This is reassuring, as field-based measures can be criticized for their lack of controls and lab-based measures for their lack of ecological relevance, as well as the confounding effects of differential response to captivity and testing by humans.

\section{Brain Areas Involved in Cognition}

In order to better understand the predicted inter-taxon relationship between cognitive measures and neural center efficiency, it would be useful to know which neural measure we should focus on: size of whole brains or of restricted areas? Volumes, neuron numbers or receptor densities? Recent work on humans, birds, rodents and non-human primates suggests possible directions. When neuroscientists look at the control centers that are involved in different cognitive tasks, the result they most often come up with is that each task involves a network of localized centers distributed in many parts of the brain. Lesion and neuronal recording techniques are useful in identifying precise areas crucial to the correct functioning of a given cognitive system, but they are incapable of mapping the whole set of areas that are active. In contrast, techniques like MRI, immediate early genes and receptor site mapping can inform us about how broad or localized should be our search for brain correlates of cognition. The techniques routinely compare neural activation during a particular cognitive task [e.g., imitation of observed movement, Iacoboni et al., 1999] to that of the closest control (e.g., movement or observation only), and thus underestimate the total number of brain areas active during cognitive processing. Bearing this in mind, the most frequent result of brain imaging studies is that a number of different localized centers distributed all over the brain are involved in each cognitive activity. For example, a meta-analysis of 64 MRI studies in humans reveals a very broad distribution of areas active in different types of human tool use situations [Lewis, 2006]. When the mapping of the areas is restricted to those that are reported in at least four of the 64 studies, eight areas in the cortex, plus areas in the cerebellum and basal ganglia appear to be involved. During macaque tool use, 10 areas show MRI activity, from different parts of the right and left cerebellum to parts of the basal ganglia and cortical areas such as the precuneus and inferior temporal cortex [Obayashi et al., 2001]. During cooperative interactions in a prisoner's dilemma game, at least five cortical and subcortical areas are active in humans [Rilling et al., 2002].

Unfortunately, brain imaging studies are usually conducted on single species and almost never compare animals that show lifestyle differences likely to affect cognition. A remarkable exception is the work of Goodson and co-authors on the neural basis of avian sociality. The work from this group uses state-of-the-art neuroscience techniques to, among other things, map the receptor density of neuropeptides involved in sociality; the sample of 
species is remarkably broad for this kind of study (five), and the authors distinguish cases of independent and phylogenetically-correlated evolution. The studies identify neurohormone receptor site differences that correlate with sociality differences in 13 different brain centers ranging from the sub-pallial septum to the stria terminalis, the hypothalamus and the hippocampus [see table 1 in Goodson et al., 2006]. In several other brain areas (e.g., the medial nidopallium, the ventral pallidum), high densities of neuropeptide binding sites are also found, even though no interspecific differences seem to be linked to significant differences in their density.

\section{Enhanced Performance of Enlarged Brain Areas}

Brains vary in whole size, size of their parts, density of neurons and glia, as well as density of neurotransmitter receptors. Each of these features has been suggested to reflect, with different levels of accuracy, the performance of the brain in cognitive tasks. The size of comparative databases on each of these measures is inversely proportional to the difficulty of obtaining data on them. Corrected endocast estimates of whole brain size from museum specimens are the easiest data to gather, whereas binding densities and neuron numbers are the most workintensive. Gross, easy-to-obtain measures are usually assumed to be temporary 'best of a bad job' estimates of finer, hard-to-obtain data. This assumption can easily be tested by calculating the proportion of variance in the fine structure that can be predicted from the gross measure. In birds, for example, residual size of the whole brain (i.e., the residuals of log-brain size regressed against log-body size) predicts $95 \%$ of the variance in residual size of the mesopallium and nidopalllium, while residual size of the telencephalon predicts 99\% [Timmermans et al., 2000]. Trends in primates are similar: $97 \%$ of the variance in residual size of the cortex is predicted by residual brain size, while $99 \%$ is predicted by residual telencephalon size [data from Stephan et al., 1981]. It is only when measures such as executive brain ratio (volume of pallial areas/brainstem) are used that the similarity between primates and birds breaks down: interspecific variance in executive ratio is well predicted by absolute size of the brain ( $89 \%)$, but not by residual size (21\%).

Herculano-Houzel and colleagues have recently contributed a crucial methodological test of assumptions by estimating the relationship between brain size and neuron numbers across six species of rodents [HerculanoHouzel et al., 2006; Herculano-Houzel, 2007] and six spe- cies of primates [Herculano-Houzel et al., 2007]. They found a very tight relationship between residuals of neuron numbers and brain size, after taking out the common effects of body size. Interestingly, the slope of this relationship differs between primates and rodents, with neuron numbers increasing at a faster rate with increasing brain size in the former than in the latter. This finding is consistent with the fact that primates have better cognitive abilities than do rodents of a similar size. It would be interesting if Goodson's comparative research program on sociality and fine level neuronal measures could address the assumptions of brain size research, for example by looking at the relationship between neuropeptide receptor density and size of structures involved in sociality such as the amygdala, the septal complex, the hypothalamus and the hippocampus.

\section{Relationship between the Size of Neural Centers and Cognitive Measures}

Selection favoring enhanced performance on a particular cognitive process is expected to drive increases in the brain areas involved. We can thus predict an association among the neuron numbers, binding density or size of a brain region and the performance on the cognitive tasks the region controls. Most of the neuroecological tests on brain evolution deal with lifestyles that are assumed to require enhanced cognitive performance, not the cognitive processes themselves. For example, the robust finding that relative size of the hippocampus is positively associated with interspecies [Lucas et al., 2004] and inter-family [Sherry et al., 1989; Krebs et al., 1989] differences in food-storing assumes a link between enhanced needs for remembering the position of stored food and enhanced neuronal performance of a larger hippocampus. Overall, comparative tests of spatial memory are in the direction predicted by the assumption, but results are not as robust and clear as those linking storing itself with hippocampal size. The literature linking song repertoire size and relative size of song production nuclei (e.g., HVC and RA) in oscines is on firmer ground. Not only is the association between repertoire and nucleus size clearly established at the inter- [DeVoogd et al., 1993] and intra-specific [Garamszegi and Eens, 2004] levels, it also appears to characterize gender differences: species in which only males sing have dimorphic song nuclei, whereas species where both sexes sing do not [Brenowitz, 1997]. In addition, evidence is accumulating that song learning coincides with neuronal growth in HVC [Zeng 
et al., 2007], that HVC and RA control different levels of song organization [Yu and Margoliash, 1996], that larger learned repertoires are reflected in increased dendritic spine density in HVC [Airey et al., 2000a], that females select for males with both a larger HVC and a larger repertoire [Airey and DeVoogd, 2000], that HVC size and song complexity predict male quality [Pfaff et al., 2007] and that both repertoire size and HVC size are inherited [Airey et al., 2000b]. Eventually, the impressive advances that characterize the song learning literature need to be imitated in other areas of neuroecology.

Research on general (as opposed to adaptively specialized) cognitive abilities has also concentrated on the link between brains and lifestyles, assuming that more complex lifestyles demand more complex cognition that demand in turn larger brains. Diet [Harvey et al., 1980; Reader and MacDonald, 2003; Ratcliffe et al., 2006] and sociality [Dunbar, 1998] have been the main lifestyle variables studied. Direct tests on brains and cognition are recent. Interspecific differences in social deception in primates are positively correlated with cortex size [Byrne, 1993; Byrne and Corp, 2004], as are differences in rates of social learning, innovation and tool use [Reader and Laland, 2002]. A similar relationship has been found for birds between residual size of pallial areas and rate of innovation [Timmermans et al., 2000] and tool use [Lefebvre et al., 2002]. Paradoxically, cognition is often unrelated with lifestyles that co-vary with brain size. Social deception rate is not significantly associated with group size [Byrne and Corp, 2004], despite the fact that both variables are associated with cortex size. More work of the type conducted on song is clearly needed on both specialized (e.g., spatial) and general cognition to understand the three-way link between lifestyle, cognitive abilities and neural control areas.

\section{Size: Whole Brains or Brain Areas? Absolute or Allometrically Corrected?}

The brain is not a homogeneous organ, but a network of pathways and centers which can vary in the degree of specialization. Its size is also strongly dependent on taxonomic grade shifts and allometry. Over the years, researchers have debated whether brains should be compared in terms of absolute size (i.e., as a whole, as well as uncorrected for allometry) or in terms of allometrically corrected size of their component parts. For the moment, studies on primates, birds and insects seem to yield divergent results on this issue. A recent analysis by Deaner et al. [2007] suggests that absolute brain size, uncorrected for allometry, is the best predictor of comparative cognitive performance in primates. Absolute size of the cortex is also a good predictor of rates of social deception [Byrne and Corp, 2004], innovation, tool use and social learning [Reader and Laland, 2002]. In insects, new insights have recently been proposed by Sarah Farris [Farris, 2005, 2008; Farris and Roberts, 2005]. The key neuroecological difference in insect brains appears to lie in the degree of gyrification of the mushroom bodies. Gyrencephalic mushroom bodies with multiple calyces characterize insects with generalist diets (e.g., Scarites subterraneus), opportunistic invasive lifestyles (e.g., cockroaches, Japanese beetles) or complex societies (e.g., honeybees, termites). In contrast, specialized insects such as flesh flies, ladybirds and dung beetles have lissencephalic mushroom bodies with single calyces. The number of Kenyon cells is also much higher in the gyrencephalic mushroom bodies of generalist beetles [Farris and Roberts, 2005]. In birds, the mesopallium and nidopallium are thought to be equivalent to the cortex of mammals. Residual size of the mesopallium is marginally better than that of other telencephalic structures in predicting innovation rate in birds [Timmermans et al., 2000], whereas that of the nidopallium is the best predictor of true tool use rate [Lefebvre et al., 2002]. Differences in $r^{2}$ are very small, however, and do not provide very robust evidence that a focus on restricted brain areas better accounts for inter-taxon variance in cognition than does a focus on the whole brain. Data on mesopallium, nidopallium, telencephalon and whole brain size are currently available on 67 avian species [Iwaniuk and Hurd, 2005]. Table 1 shows that the average partial correlation with tool use and innovation rate is not higher when pallial components are used than when the anatomical level chosen is the whole brain. Table 1 also shows that, contrary to the situation in primates, absolute size of the brain or of pallial areas is unrelated to differences in innovation and tool use rates. Finally, different kinds of allometric corrections all seem to produce similar results in birds, whether they be residuals of regressions against log body size, executive brain ratios (volume of the mesopallium plus nidopallium divided by volume of the brainstem) or EQ [using the equation of Martin, 1981]. For the moment, the data on insects, primates and birds thus do not yield a clear consensus on the neural level that best predicts cognitive differences within each group. 


\section{Genetic Variation in Brain Size}

If variation in the size, gyrification or neuron numbers of brain areas is a key correlate of adaptive cognitive differences between taxa, we should be able to identify genetic differences that lead to neural changes. Recent work on mice and humans provides interesting examples of such genetic effects. In mice, transgenic individuals that express an abnormal form of B-catenin in neural precursors show large increases in brain size due to extension of the surface area of the cortex leading to strong gyrification [Chen and Walsh, 2002]. In humans, single genes that in their abnormal form cause primary microcephaly (ASPM and MCPH1) show allelic variation suggestive of positive selection in contemporary human populations [Mekel-Bobrov et al., 2005; Evans et al., 2005; Vallender, 2008]. The phylogenetic history of ASPM and microcephalin genes shows faster rates of positive selection in the branches that separate humans and chimpanzees, as well as the branches that separate apes from Old World monkeys [Kouprina et al., 2004]. The implications of this genetic variation for cognition are for the moment obscure. Inter-population variation in ASPM and MCPH1 alleles shows no consistent relationship with performance on IQ tests [Mekel-Bobrov et al., 2007], but does seem to show an intriguing degree of correspondence with tonal versus atonal features of different languages [Dediu and Ladd, 2007].

\section{Selective Pressures Favoring Larger Brains}

Many studies on ecological correlates of whole brain size assume that natural, not sexual, selection drives the co-evolution. Instead, sexual selection is usually thought to produce changes in restricted brain areas involved in modular specializations [e.g., song nuclei, the hippocampus of brood parasites and polygynous rodents; see Jacobs, 1996 for a review]. Sexual selection often leads to reduction in whole brain size, as animals invest instead in costly traits that allow them to attract mates (bright colors, intricate displays, exaggerated structures) or outcompete individuals of their own sex (large size, large fertilization organs, combat structures). For example, there appears to be a trade-off in bats between relative size of the brain and of the testes [Pitnick et al., 2006]. In primates, species with large size dimorphism tend to have smaller brains than those that are more monomorphic [Schillaci, 2006]. Selection on brain areas also appears to be sex-specific in this order; brain evolution in males ap-
Table 1. Mean proportion of variance in innovation and tool use rate explained by neural size measures

Residual whole brain against body weight 0.37 Residual telencephalon against body weight 0.38 Residual mesopallium against body weight

Residual nidopallium against body weight

0.37

Executive ratio (nidopallium + mesopallium/brainstem) $\quad 0.35$

EQ [equation from Martin, 1981]

Absolute brain size

0.36

0.01

Absolute mesopallium and nidopalium volume

0.01

Based on raw data from Iwaniuk and Hurd [2005]. All specieslevel $(n=67)$ neural and body size measures first averaged at the level of the parvorder $(n=22)$. Values in the right column are means of the $r^{2}$ of the regressions of each neural measure against innovation rate, on the one hand, and tool use rate on the other [data from Lefebvre et al., 2004].

pear to have been driven by physical conflict, whereas socio-cognitive skills seem to have been the main driver in females [Lindefors et al., 2007]. Exceptions to this generally negative relationship between brain size and sexual selection are bower birds and zebra finches. In the family Ptilonorhynchidae, species that build more complex bowers have larger brains [Madden, 2001; see however Day et al., 2005] and/or cerebella [Day et al., 2005] than those that either build simpler bowers or no bowers at all. Zebra finches that sing more complex songs have both a larger HVC and telencephalon than those that sing simpler songs; song complexity and size of both the HVC and the whole telencephalon are heritable in this species [Airey et al., 2000b]. Whether these trends occur in other species needs to be determined. Bowerbird females prefer males that build more complicated bowers (and bowers that incorporate colors from local foods), and female zebra finches prefer males that sing more complex songs. As more complex zebra finch songs are associated both with a larger HVC and a larger telencephalon [Airey et al., 2000b], and more complex bowers associated with a larger brain [Madden, 2001] or cerebellum [Day et al., 2005], female choice is sexually selecting for the size of neural structure size. In polygynous meadow voles, females prefer males with better spatial ability; spatial ability in this species is associated with a larger hippocampus, again resulting in sexual selection for neural structure size [Spritzer et al., 2005]. Paradoxically, Spritzer et al. [2005] found that males with better spatial abilities attract more mates, but they were not able to show that these males father more offspring [see Sherry, 2006 for a discussion]. 
The natural selection forces that have been suggested to shape brain size evolution mostly emphasize the need for enhanced cognition in three main contexts, foraging, parental care and social relationships. The pioneeering work in this area originated in the late 1970's and early 1980's, centered around Paul Harvey, Tim Clutton-Brock and Peter Bennett, and focused on categorical measures of ecological correlates [e.g., diet, Harvey et al., 1980] of brain size. Continuous variables were then added, most notably size of the social unit [Sawaguchi and Kudo, 1990; Perez-Barberia et al., 2007]. In all cases, the association with brain size assumes an untested cognitive intermediary: larger neural centers allow some animals to be more flexible than others in their foraging techniques [Reader and Laland, 2002; Ricklefs, 2004; Ratcliffe et al., 2006], better able to monitor spatial and temporal variation of patchy food sources [e.g., fruit, Clutton-Brock and Harvey, 1980], process information about multiple food types [Reader and MacDonald, 2003], or better interact with more social partners [Dunbar, 1998], detect and rapidly capture evasive prey [Gittleman, 1986], extract rare hidden foods [Parker and Gibson, 1977] and/or program a larger repertoire of foraging patterns [Changizi, 2003]. These presumed functions are not mutually exclusive and several or all of them might have contributed to brain size evolution in a given taxon. Pollen et al. [2007] showed for example that physical and social variables affecting cichlid brain evolution are highly correlated. In fact, physical and social variables might be driven by common ecological factors. The more a food is clumped and predictable in time and space, the more an animal can specialize on it and exploit it alone, driving others away. The solitary-group living continuum and the specialist-generalist continuum may thus vary together, as shown in a recent model [Overington et al., in press], and ecological and social theories of cognition might thus have more in common than is often assumed.

The fitness benefits of large brains have never been directly quantified within any population, but recent comparative analyses in birds and mammals suggest that large brain size might enhance survival in nature. In birds, mean adult mortality is lower in populations, species and families with larger brains, after the effect of other factors known to influence mortality (the most important being body size) have been taken out [Sol et al., 2007]. In birds [Sol et al., 2005] and mammals [Sol et al., in press], but not in fish [Drake, 2007], the long-term survival of populations introduced by humans outside their natural range is higher in species with larger brains, an association that is largely independent of other factors that influence the invasion process. Results on avian and mammalian introductions suggest that environmental change might be a key factor in the evolution of enlarged brains.

\section{Convergent Brain Size Evolution among Taxa}

In birds and primates, there appears to be a remarkable degree of convergence in the relationship between pallial area size, innovation rate, tool use and reversal learning [Lefebvre et al., 2004]. Does this imply that the evolution of larger brains and brain areas have been driven by similar selective pressures? The finding that brain size facilitates survival in novel regions in birds [Sol et al., 2005] as well as mammals [Sol et al., in press] suggests some convergence in the adaptive function of the brain. For social variables, the relationship also appears to be convergent, but shows some complications. In primates, social group size, social learning and social deception are all positively correlated with size of the pallial area. In birds, the relationship between brain size and social group size appears to be curvilinear rather than linear [Emery et al., 2007]; beyond group sizes of 70, animal numbers seem to be too large to allow the individual recognition and relationships that would put a premium on social computing powers of the brain. The relationship between social learning and the brain is also difficult to establish in birds because the number of reported cases of social learning in the wild is both small and strongly skewed towards a single taxon: oscines [Lefebvre and Bouchard, 2003]. The idea that a broader diet might be one of the main drivers of brain and cognitive evolution is supported in birds [Overington et al., in press], in primates [Reader and MacDonald, 2003], in bats [Ratcliffe et al., 2006] and in insects [Farris and Roberts, 2005; Farris, 2005, 2008]. In fish, brain size differences between cichlid species correlate with mating system, habitat complexity and interspecific competition [Pollen et al., 2007; Shumway, 2008], suggesting that in this taxon also, lifestyles that demand more information-processing seem to select for larger brains and brain areas.

\section{Conclusion}

Comparative and experimental approaches to animal cognition show largely consistent results. Similar trends associated with similar lifestyles are also seen in taxa that are phylogenetically distant and possess remarkably dif- 
ferent brains. Many cognitive measures show positive intercorrelations at the inter-individual and inter-taxon level; ecological principles such as the unpredictability of resources in space and time might drive different types of cognition (e.g., social and non-social) in the same direction. If different cognitive activities involve networks of localized centers distributed in many areas of the brain and if most of these cognitive activities are positively correlated across individuals and species, then we need to incorporate this into our thinking about brain evolution. Imagine two species that differ on four cognitive measures, each one of which involves in turn eight distributed brain centers. Among New World monkeys, for example, marmosets and capuchins show clear differences in rates of innovation, tool use, social learning, as well as reversal learning speed. In all four cases, capuchins outrank marmosets, as they do on measures of absolute and relative size of the whole brain and cortex. In the 20 to 25 million years since the marmoset and capuchin lineages split, how did divergent evolution of their brains and cognition occur? By separate changes in the genes affecting each of the 32 brain centers involved in the four cognitive processes? By a limited number of genetic changes that had broad consequences all over the brain? To more efficiently tackle these questions, we need more comparative data on fine neural differences in animals that show divergent lifestyles, of the type that Goodson and his group have gathered on avian sociality. We need to iden- tify more gene changes that are associated with neural differences, be they changes that could affect the whole brain [Kouprina et al., 2004; Evans et al., 2005; MekelBobrov et al., 2005, 2007; Vallender, 2008] or cortex [Chen and Walsh, 2002] or localized centers. We need brain imaging data on batteries of cognitive processes that are either positively (e.g., reversal learning, social learning, and tool use) or negatively (spatial memory) correlated across taxa. Finally, we need to identify the evolutionary processes that drive increases in brain size, integrating retrospective approaches where present-day brain-ecology associations are linked to historical events, as well as prospective approaches, asking how present ecological conditions select for enhanced cognitive skills and larger brains. Only when we assemble enough evidence for all these issues we will be able to construct a general theory for the evolution of large brains.

\section{Acknowledgements}

This paper is dedicated to the memory of Georg Baron (who died in 2007), co-author of the most widely used database on primate [Stephan et al., 1981], insectivore and bat brain component size, and professor (to L.L., among others) of animal behavior at the Université de Montréal. We thank Andrew Iwaniuk for providing access to the raw data used in Iwaniuk and Hurd [2005]. D.S. is supported by a Ramón y Cajal fellowship and a Proyecto de Investigación (CGL2007-66257) from the Ministerio de Educación y Ciencia (Spain). L.L. is supported by NSERC (Canada).

\section{References}

Airey DC, DeVoogd TJ (2000) Variation in song complexity and $\mathrm{HBC}$ volume are significantly related in zebra finches. NeuroReport 10: 2339-2344.

Airey DC, Kroodsma DE, DeVoogd TJ (2000a) Differences in the complexity of song tutoring cause differences in the amount learned and in dendritic spine density in a songbird telencephalic song control nucleus. Neurobiol Learn Mem 73:274-281.

Airey DC, Castillo-Juarez H, Casella G, Pollak EJ, DeVoogd TJ (2000b) Variation in the volume of zebra finch song control nuclei is heritable: developmental and evolutionary implications. Proc R Soc Lond B 267:20992104.

Bennett PM, Harvey PH (1985) Relative brain size and ecology in birds. J Zool 207:151169.

Bonnie KE, Horner V, Whiten A, de Waal FBM (2007) Spread of arbitrary conventions among chimpanzees: a controlled experiment. Proc R Soc Lond B 274:367-372.
Bouchard J, Goodyer W, Lefebvre L (2007) Innovation and social learning are positively correlated in pigeons. An Cog 10:259-266.

Brenowitz EA (1997) Comparative approaches to the avian song system. J Neurobiol 33:517531.

Brosnan SF, Grady MF, Lambeth SP, Schapiro SJ, Beran MJ (2008) Chimpanzee autarky. PloS One 3:e1518.

Byrne RW, Corp N (2004) Neocortex size predicts deception rate in primates. Proc R Soc Lond B 271:1693-1699.

Byrne RW, Whiten A (eds) (1988) Machiavellian Intelligence: Social Expertise and the Evolution of Intellect in Monkeys, Apes and $\mathrm{Hu}$ mans. Oxford, UK: Oxford University Press.

Byrne RW (1993) Do larger brains mean greater intelligence? Behav Brain Sci 16:696-697.

Changizi MA (2003) Relationship between number of muscles, behavioral repertoire size, and encephalization in mammals. J Theor Biol 220:157-168.
Chen A, Walsh CA (2002) Regulation of cerebral cortical size by control of cell cycle exit in neural precursors. Science 297:365-369.

Clutton-Brock TH, Harvey PH (1980) Primates, brain and ecology. J Zool Lond 190:309323.

Day LB, Westcott DA, Olster DH (2005) Evolution of bower complexity and cerebellum size in bowerbirds. Brain Behav Evol 66:6272.

Deaner, Ro, van Scahik, CP, Johnson V (2006) Do some taxa have better domaon-general cognition than others? A meta-analysis of non-human primate studies. Evol Psych 4: 149-196.

Deaner RO, Isler K, Burkart J, van Schaik C (2007) Overall brain size, and not encephalization quotient, best predicts cognitive ability across non-human primates. Brain Behav Evol 70:115-124. 
Dediu D, Ladd DR (2007) Linguistic tone is related to the population frequency of the adaptive haplogroups of two brain size genes, ASPM and microcephalin. Proc Natl Acad Sci USA 104:10944-10949.

DeVoogd TJ, Krebs JR, Healy SD, Purvis A (1993) Relations between song repertoire size and the volume of brain nuclei related to songcomparative evolutionary analyses amongst oscine birds. Proc R Soc Lond B 254:75-82.

Drake JM (2007) Parental investment and fecundity, but not brain size, are associated with establishment success in introduced fishes. Funct Ecol 21:963-968.

Drapier M, Chauvin C, Dufour V, Uhlrich P, Thierry B (2005) Food-exchange with humans in brown capuchin monkeys. Primates 46:241-248.

Dunbar RIM (1998) The social brain hypothesis. Evol Anthropol 6:178-190.

Emery NJ, Seed AM, von Bayern AMP, Clayton NS (2007) Cognitive adaptations of social bonding in birds. Phil Trans R Soc B 362: 489-505.

Evans PD, Gilbert SL, Mekel-Bobrov N, Vallender EJ, Anderson JR, Vaez-Azizi LM, Tishkoff SA, Hudson RR, Lahn BT (2005) Microcephalin, a gene regulating brain size, continues to evolve adaptively in humans. Science 309:1717-1720.

Farris SM (2005) Evolution of insect mushroom bodies: old clues, new insights. Arthr Struc Dev 34:211-234.

Farris SM (2008) Evolutionary convergence of higher brain centers spanning the protostome-deuterostome boundary. Brain Behav Evol 72:106-122.

Farris SM, Roberts NS (2005) Coevolution of generalist feeding ecologies and gyrencephalic mushroom bodies in insects. Proc Natl Acad Sci USA 102:17394-17399.

Fragaszy D, Izar P, Visalberghi E, Ottoni EB, De Oliveira MG (2004) Wild capuchin monkeys (Cebus libidinosus) use anvils and stone pounding tools. Am J Primatol 64:359-366.

Garamszegi LZ, Eens M (2004) Brain space for a learned task: strong intraspecific evidence for neural correlates of singing behavior in songbirds. Brain Res Rev 44:187-193.

Giraldeau LA, Lefebvre L, Morand-Ferron J (2007) Can restrictive definitions lead to biases and tautologies? Behav Brain Sci 30: 411-412.

Gittleman JL (1986) Carnivore brain size, behavioural ecology, and phylogeny. J Mammal 67: 23-36.

Goodson JL, Evans AK, Wang Y (2006) Neuropeptide binding reflects convergent and divergent evolution in species-typical group sizes. Horm Behav 50:223-236.

Griffin AS, Galef BG Jr (2005) Social learning about predators: does timing matter? Anim Behav 69:669-678.

Harvey PH, Clutton-Brock TH, Mace GM (1980) Brain size and ecology in small mammals and primates. Proc Natl Acad of Sci USA 77: 4387-4389.
Herculano-Houzel S (2007) Encephalization, neuronal excess, and neuronal index in rodents. Anat Rec 290:1280-1287.

Herculano-Houzel S, Mota B, Lent R (2006) Cellular scaling rules for rodent brains. Proc Natl Acad Sci USA 103:12138-12143.

Herculano-Houzel S, Collins CE, Wong PY, Kaas JH (2007) Cellular scaling rules for primate brains. Proc Natl Acad Sci USA 104: 3562-3567.

Hunt GR (1996) Manufacture and use of hooktools by New Caledonian crows. Nature 379: 249-251.

Hunt GR, Gray RD (2004) Direct observations of pandanus-tool manufacture and use by a New Caledonian crow (Corvus moneduloides). Anim Cogn 7:114-120.

Iacoboni $\mathrm{M}$, Woods RP, Brass $\mathrm{M}$, Bekkering $\mathrm{H}$, Mazziotta JC, Rizzolatti G (1999) Cortical mechanisms of human imitation. Science 286:2526-2528.

Iwaniuk AN, Hurd PL (2005) The evolution of cerebrotypes in birds. Brain Behav Evol 65: 215-230.

Iwaniuk AN, Nelson JE (2003) Developmental differences are correlated with relative brain size in birds: a comparative analysis. Can J Zool 81:1913-1928.

Jacobs LF (1996) Sexual selection and the brain. Trends Ecol Evol 11:A82-A86.

Jerison HJ (1973) Evolution of the Brain and Intelligence. New York: Academic Press.

Kenward B, Weir AAS, Rutz C, Kacelnik A (2005) Tool manufacture by naïve juvenile crows. Nature 433:121-121.

Kouprina N, Pavlicek A, Solomon G, Gersch W, Yoon YH, Collura R, Ruvolo M, Barrett JC, Woods CG, Walsh CA, Jurka J, Larionov V (2004) Accelerated evolution of the ASPM gene controlling brain size begins prior to human brain expansion. PLoS Biol 2:653663.

Krebs JR, Sherry DF, Healy SD, Perry H, Vaccarino AL (1989) Hippocampal specialization in food storing birds. Proc Natl Acad Sci USA 86:1388-1392.

Lefebvre L, Bouchard J (2003) Social learning about food in birds. In: The Biology of Traditions (Perry S, Fragaszy DM, eds), pp 94-126. Cambridge, UK: Cambridge University Press.

Lefebvre L (1982) Food exchange strategies in an infant chimpanzee. J Human Evol 11:195204.

Lefebvre L, Bolhuis JJ (2003) Positive and negative correlates of feeding innovations in birds: evidence for limited modularity. In: Animal Innovation (Reader SM, Laland KN, eds), pp 39-62. Oxford, UK: Oxford University Press.

Lefebvre L, Juretic N, Timmermans S, Nicolakakis N (2001) Is the link between innovation rate and forebrain size caused by confounding variables? A test on North American and Australian birds. Anim Cogn 4:91-97.

Lefebvre L, Nicolakakis N, Boire D (2002) Tools and brains in birds. Behaviour 139:939-973.
Lefebvre L, Reader SM, Sol D (2004) Brains, innovations and evolution in birds and primates. Brain Behav Evol 63:233-246.

Lefebvre L, Whittle P, Lascaris E, Finkelstein A (1997a) Feeding innovations and forebrain size in birds. Anim Behav 53:549-560.

Lefebvre L, Templeton J, Brown K, Koelle M (1997b) Carib grackles imitate conspecific and Zenaida dove tutors. Behaviour 134: 1003-1017.

Lewis JW (2006) Cortical networks related to human use of tools. Neuroscience 2:211231.

Lindefors P, Nunn CL, Barton RA (2007) Primate brain architecture and selection in relation to sex. BMC Biol 5:20.

Lucas JR, Brodin A, de Kort SR, Clayton NS (2004) Does hippocampal size correlate with the degree of caching specialization? Proc $\mathrm{R}$ Soc Lond B 271:2423-2429.

Madden J (2001) Sex, bowers and brains. Proc R Soc Lond B 268:833-838.

Martin RD (1981) Relative brain size and basal metabolic-rate in terrestrial vertebrates $\mathrm{Na}$ ture 293:57-60.

Mekel-Bobrov N, Gilbert SL, Evans PD, Vallender EJ, Anderson JR, Hudson RR, Tishkoff SA, Lahn BT (2005) Ongoing adaptive evolution of ASPM, a brain size determinant in Homo sapiens. Science 309:1720-1722.

Mekel-Bobrov N, Posthuma D, Gilbert SL, Lind P, Gosso MF, Luciano M, Harris SE, Bates TC, Polderman TJC, Whalley LJ, Fox H, Starr JM, Evans PD, Montgomery GW, Fernandes C, Heutink P, Martin NG, Boomsma DI, Deary IJ, Wright MJ, de Geus EJC, Lahn BT (2007) The ongoing adaptive evolution of ASPM and Microcephalin is not explained by increased intelligence. Hum Mol Genet 16:600-608.

Melis AP, Hare B, Tomasello M (2006) Chimpanzees recruit the best collaborators. Science 311:1297-1300.

Morand-Ferron J, Lefebvre L, Reader SM, Sol D, Elvin S (2004) Dunking behaviour in Carib grackles. Anim Behav 68:1267-1274.

Morand-Ferron J, Veillette M, Lefebvre L (2006) Stealing of dunked food in Carib grackles (Quiscalus lugubris). Behav Proc 73:342347.

Morand-Ferron J, Giraldeau LA, Lefebvre L (2007a) Wild carib grackles play a producerscrounger game. Behav Ecol 18:916-921.

Morand-Ferron J, Lefebvre L (2007b) Flexible expression of a food-processing behaviour: determinants of dunking rates in wild Carib grackles of Barbados. Behav Proc 76:218221.

Moura ACD, Lee PC (2004) Capuchin stone tool use in Caatinga dry forest. Science 306:19091909.

Nicolakakis N, Lefebvre L (2000) Innovation rate and forebrain size in birds of western Europe: feeding, nesting and confounding variables. Behaviour 137:1415-1429. 
Obayashi S, Suhara T, Kawabe K, Okauchi T, Maeda J, Akine Y, Onoe H, Iriki A (2001) Functional brain mapping of monkey tool use. Neuroimage 14:853-861.

Orenstein RI (1972) Tool-use by Caledonian crow (Corvus moneduloides). Auk 89:674676.

Overington SE, Dubois F, Lefebvre L (2008) Food unpredictability drives both generalism and social foraging: a game theoretical model. Behav Ecol 19:836-841.

Parker ST, Gibson KR (1977) Object manipulation, tool use and sensorimotor intelligence as feeding adaptations in cebus monkeys and great apes. J Hum Evol 6:623-641.

Perez-Barberia FJ, Shultz S, Dunbar RIM (2007) Evidence for coevolution of sociality and relative brain size in three orders of mammals. Evolution 61:2811-2821.

Pfaff JA, Zanette L, MacDougall-Shackleton SA, MacDougall-Shackleton EA (2007) Song repertoire size varies with HVC volume and is indicative of male quality in song sparrows (Melospiza melodia). Proc R Soc Lond B 274: 2035-2040.

Pitnick S, Jones KE, Wilkinson GS (2006) Mating system and brain size in bats. Proc R Soc Lond B 273:719-724.

Plomin R (2001) The genetics of $g$ in human and mouse. Nature Rev Neurosci 2:136-141.

Pollen AA, Dobberfuhl AP, Scace J, Igulu MM, Renn SCP, Shumway CA, Hofmann HA (2007) Environmental complexity and social organization sculpt the brain in Lake Tanganyikan cichlid fish. Brain Behav Evol 70: 21-39.

Ratcliffe JM, Fenton MB, Shettleworth SJ (2006) Behavioral flexibility is positively correlated with relative brain volume in predatory bats. Brain Behav Evol 67:165-176.
Reader SM, Laland KN (2002) Social intelligence, innovation and enhanced brain size in primates. Proc Natl Acad Sci USA 99: 4436-4441.

Reader SM, MacDonald K (2003) Environmental variability and primate behavioural flexibility. In: Animal Innovation (Reader SM, Laland $\mathrm{KN}$, eds), pp 83-116. Oxford, UK: Oxford University Press.

Ricklefs RE (2004) The cognitive face of avian life histories - The 2003 Margaret Morse Nice Lecture. Wilson Bull 116:119-133.

Rilling JK, Gutman DA, Zeh TR, Pagnoni G, Berns GS, Kilts CD (2002) A neural basis for social cooperation. Neuron 35:395-405.

Sawaguchi T, Kudo H (1990) Neocortical development and social-structure in primates. Primates 31:283-289.

Schillaci MA (2006) Sexual selection and the evolution of brain size in primates. PloS One 1:e62.

Sherry DF (2006) Neuroecology. Ann Rev Psychol 57:167-197.

Sherry DF, Schacter DL (1987) The evolution of multiple memory-systems. Psychol Rev 94: 439-454.

Sherry DF, Vaccarino AL, Buckenham K Herz RS (1989) The hippocampal complex of foodstoring birds. Brain Behav Evol 34:308-317.

Shumway C (2008) Habitat complexity, brain, and behavior. Brain Behav Evol 72:123-134.

Sol D, Bacher S, Reader SM, Lefebvre L (in press) Brain size predicts the success of mammal species introduced into novel environments. Am Nat (in press).

Sol D, Duncan RP, Blackburn TM, Cassey P, Lefebvre L (2005) Big brains, enhanced cognition, and response of birds to novel environments. Proc Natl Acad Sci USA 102: 5460-5465.

Sol D, Szekely T, Liker A, Lefebvre L (2007) Big brained birds survive better in nature. Proc R Soc Lond B 274:763-769.
Spritzer MD, Meikle DB, Solomon NG (2005) Female choice based on male spatial ability and aggressiveness among meadow voles Anim Behav 69:1121-1130.

Stephan H, Frahm H, Baron G (1981) New and revised data on volumes of brain structures in insectivores and primates. Folia Primatol $35: 1-29$.

Taylor AH, Hunt GR, Holzhaider JC, Gray RD (2007) Spontaneous metatool use by New Caledonian crows. Current Biol 17:15041507.

Timmermans S, Lefebvre L, Boire D, Basu P (2000) Relative size of the hyperstriatum ventrale is the best predictor of innovation rate in birds. Brain Behav Evol 56:196-203.

Vallender EJ (2008) Exploring the Origins of the Human Brain through Molecular Evolution. Brain Behav Evol 72:168-177.

Visalberghi E, Fragaszy DM. (1990) Do monkeys ape? In: Language and Intelligence in Monkeys and Apes (Parker ST, Gibson KR, eds), pp 247-273. Cambridge, UK: Cambridge University Press.

Webster S, Lefebvre L (2001) Problem-solving and neophobia in a Passeriforme Columbiforme assemblage in Barbados. Anim Behav 62:23-32.

Weir AAS, Chappell J, Kacelnik A (2002) Shaping of hooks in new Caledonian crows. Science 297:981.

Whiten A, Custance DM, Gomez JC, Teixidor P, Bard KA (1996) Imitative learning of artificial fruit processing in children (Homo sapiens) and chimpanzees (Pan troglodytes). J Comp Psychol 110:3-14.

Zeng SJ, Song K, Xu N, Zhang XW, Zuo MX (2007) Sex difference in cellular proliferation within the telencephalic ventricle zone of Bengalese finch. Neurosci Res 58:207214.

Zentall TR (2004) Action imitation in birds. Learn Behav 32:15-23. 